\title{
The supramolecular structure of thiazolo[3,4-a]quinoxalines: hydrogen bonding and amphiphilic properties
}

\author{
Aidar T. Gubaidullin*, Vakhid A. Mamedov, and Igor A. Litvinov \\ A. E. Arbuzov Institute of Organic and Physical Chemistry, Russian Academy of Sciences, \\ Arbuzov str. 8, Kazan, 420088, Russian Federation \\ E-mail: aidar@iopc.knc.ru
}

Dedicated to Professor Alexander I. Konovalov on the occasion of his $70^{\text {th }}$ anniversary

(received 13 Oct 04; accepted 03 Feb 05; published on the web 12 Feb 05)

\begin{abstract}
The structure of the series of new thiazolo[3,4-a]quinoxalines are described. X-ray crystal structure determination reveals significant differences in supramolecular structures of substituted thiazolo[3,4-a]quinoxalines which depends on whether the solvent molecules are involved in the crystal formation. It was shown that the separation of hydrophilic and hydrophobic regions observed in the crystals might be considered in the terms of the theory of microphase separation in block polymers. The type of supramolecular structures was found to depend on the volume ratio of hydrophilic-hydrophobic molecular fragments.
\end{abstract}

Keywords: Thiazoles, thiazolo[3,4-a]quinoxalines, X-ray crystal structure determination, supramolecular architectures, amphiphilicity

\section{Introduction}

The compounds of diazine family are one of the most important groups of biologically active heterocycles. Among them polycondensed heterocycles, containing a 1,4-diazine fragment, such as folic acid, riboflavine, tetrahydrobiopterin, kxantopterin play an important role in the physiological process. ${ }^{1}$ Various derivatives of quinoxaline possess a wide spectrum of biological activity, including antimicrotubule, antitumor and antivirus activity, including AIDS. ${ }^{2-4}$

We have recently reported a suitable method of the synthesis of thiazolo[3,4- $a$ ]quinoxalines on the basis of the condensations of the intermediate products of the Hantzsch reactions - 4hydroxythiazolidines with 1,2-phenylenediamines. ${ }^{5-6}$

In this paper we report the molecular structure and crystallographic peculiarities of novel synthesized thiazolo[3,4-a]quinoxalines $(\mathbf{1}, \mathbf{2}, \mathbf{3})$. 
<smiles>O=c1[nH]c2ccccc2n2c(=Nc3ccccc3)sc(-c3ccccc3)c12</smiles>

1<smiles>O=c1[nH]c2ccc([N+](=O)[O-])cc2n2c(=Nc3ccccc3)sc(-c3ccccc3)c12</smiles>

2<smiles>Cc1ccc2c(c1)[nH]c(=O)c1c(-c3ccccc3)sc(=Nc3ccccc3)n12</smiles>

3

It should be noted, that besides the usual approach to the study of supramolecular structures based on the analysis of hydrogen bonding and other weak interactions, we have used an additional approach based on the model of localization of hydrophilic and hydrophobic regions in organic crystals, which we revealed earlier ${ }^{7-8}$. The latter model was used for analyzing the supramolecular structure not only of quinoxalines but also of similar compounds.

\section{Results and Discussion}

Dimethylsulfoxide (DMSO) solvate of 1-arylimino-3-phenyl-4,5-dihydro-2-oxo-thiazolo[3,4a]-quinoxaline (1). The crystals of $\mathbf{1}$ were obtained in the form of inclusion compound with the solvate DMSO molecule in stoichiometry 1:1. The molecules are located in a general position in crystal (Figure 1). The lack of large substituents in the benzofragment of the tricycle moiety results in the planarity of the cyclic fragment of the molecule (standard deviation within $0.0056(5) \AA)$. The dihedral angles between the heterocyclic plane and the benzene cycles (C31$\mathrm{C} 35)$ and (C11-C16) are 50.4(2) ${ }^{\circ}$ and $87.8(2)^{\circ}$ respectively.

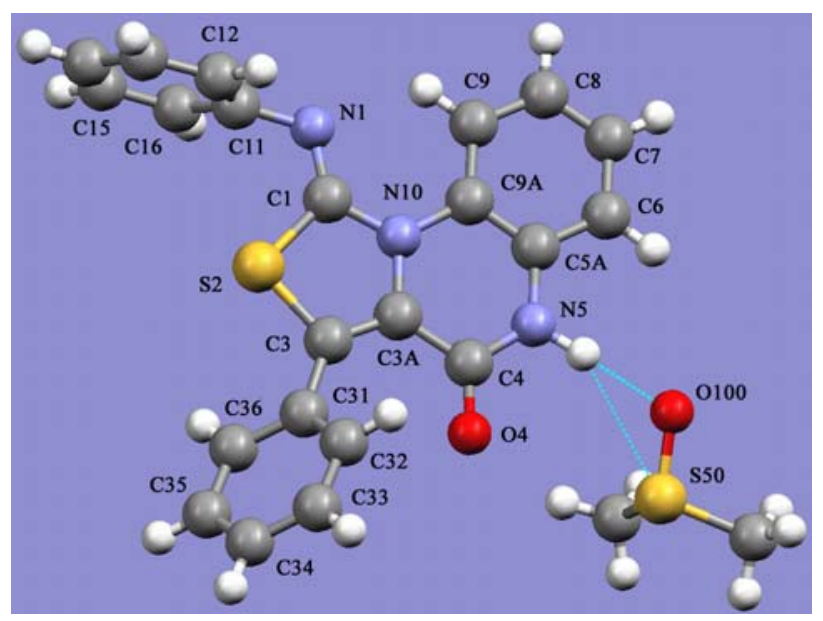

Figure 1. PLUTO drawing of the compound (1) and atom labelling scheme. Hydrogen bonds are shown by a dashed line. 
Strong intermolecular interactions of atom H5 of the molecule (1) with the oxygen O100 and sulfur S50 atoms of the DMSO molecule were observed in the crystal with the following parameters of interactions: $\mathrm{d}(\mathrm{H} 5 \ldots \mathrm{O} 100) 1.84(4) \AA ̊(\mathrm{~N} 5-\mathrm{H} 5 . . \mathrm{O} 100) 176(3)^{\circ}$ and $\mathrm{d}(\mathrm{H} 5 \ldots \mathrm{S} 50)$ $2.83(3) \AA,<(\mathrm{N} 5-\mathrm{H} 5 . . \mathrm{S} 50) 149(3)^{\circ}$ respectively. Interactions of a $\pi-\pi$ type were observed only between the pairs of molecules linked by the symmetry operation $(2-x, 2-y,-z)$. The distance between planes is 3.43(3) $\AA$ and the dihedral angle is $0^{\circ}$. These dimers of molecules are surrounded by solvate DMSO molecules (Fig.2). Their hydrogen bonds with dimers leads to the formation of a two-dimensional layered supramolecular structure. The inner part of these layers consists of hydrophilic tricyclic fragments of molecules and solvate DMSO molecules, and the external part - of hydrophobic phenyl substituents. Each successive layer is rotated $90^{\circ}$ from the previous one.

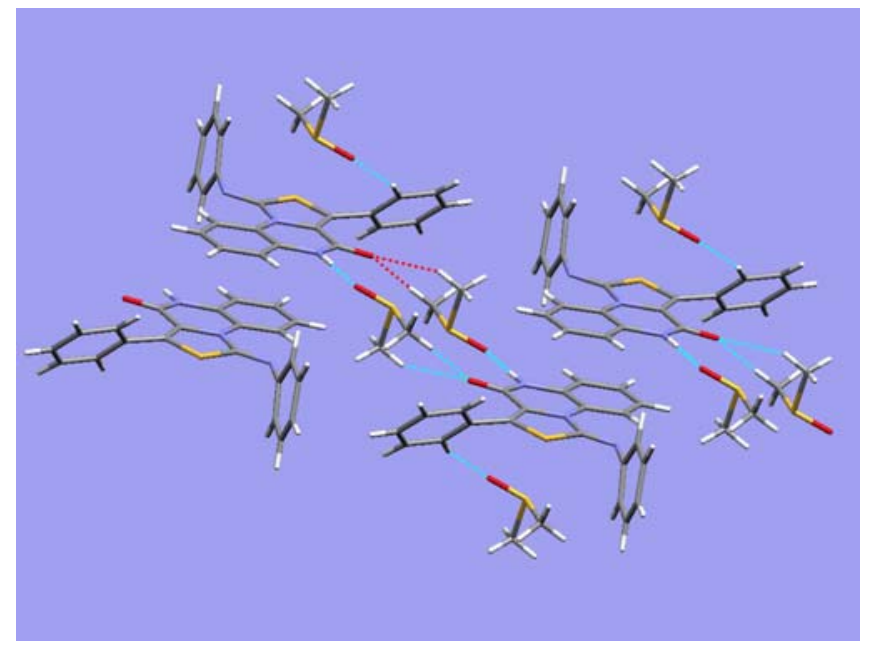

Figure 2. Intermolecular interactions in the crystal of (1).

Dimethylformamide (DMF) solvate of 1-arylimino-3-phenyl-8-nitro-4,5-dihydro-2-oxothiazolo[3,4-a]quinoxaline (2). Thiazolo[3,4-a]quinoxaline (2) molecule forms the inclusion compound with DMF in a crystal. The asymmetric part of the unit cell contains one molecule of (2) and one solvate (DMF) molecule (Figure 3). The tricyclic system is planar (standard deviation within $0.05(2) \AA)$. The conjugation in the tricyclic system is presumably the cause of its planarity. The dihedral angles between the heterocyclic plane and the benzene rings (C31-C35) and $(\mathrm{C} 11-\mathrm{C} 16)$ are $57.8(3)^{\circ}$ and $72.0(3)^{\circ}$ respectively. The nitro group of the benzofragment is located in the tricycle plane (torsion angle O81-N8-C8-C9 is $6(1)^{\circ}$ ) as a result of a long chain conjugation formed in the tricycle system. This is confirmed by the planar trigonal configuration of the nitrogen atoms and by the equalization of bond distances in the tricycle system. 


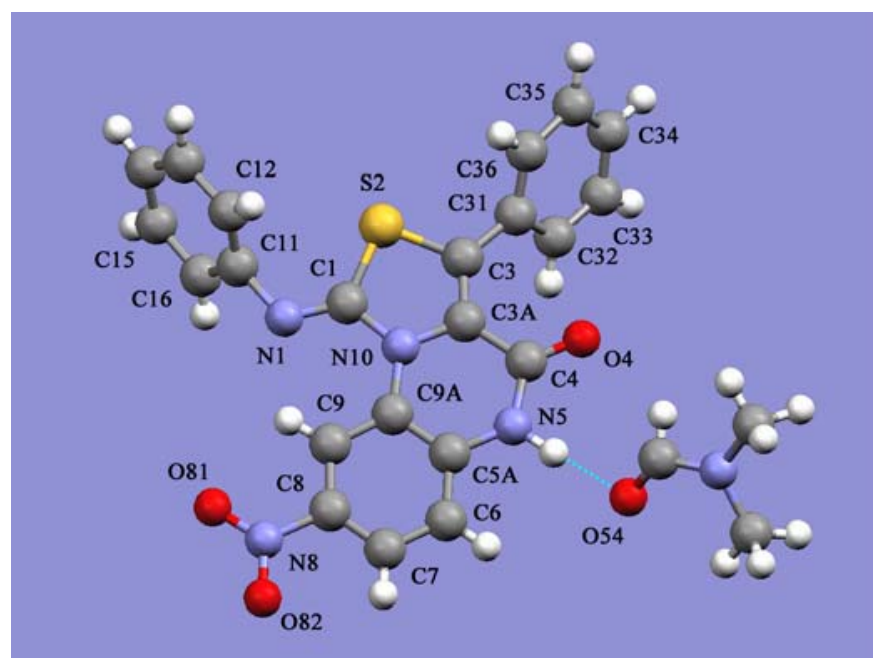

Figure 3. Geometry of the compound (2) in crystal and hydrogen bond with solvate DMF molecule (dashed line).

Various types of intra- and intermolecular interactions, including both classic N-H...O and weak C-H...O, C-H...S and $\pi$-interactions have been observed in the crystal of (2). The principal intramolecular interaction is the bifurcate bonding of $\mathrm{H} 9$ proton with the oxygen atom $\mathrm{O} 81$ of the nitro group and the nitrogen atom N1. The parameters of interaction are as follows: $\mathrm{d}(\mathrm{H} 9 . . \mathrm{O} 81)$ $2.35 \AA,<(\mathrm{C} 9-\mathrm{H} 9 . . \mathrm{O} 81) 101^{\circ}$ and d(H9...N1) $2.22 \AA,<(\mathrm{C} 9-\mathrm{H} 9 . . \mathrm{N} 1) 121^{\circ}$.

Each molecule of the compound is connected with three solvate molecules by hydrogen bonds of $\mathrm{N}-\mathrm{H} . . . \mathrm{O}$ and $\mathrm{C}-\mathrm{H} . . . \mathrm{O}$ types. Owing to the $\pi-\pi$ interaction between tricyclic moieties, linked by the symmetry operation $(1-\mathrm{x}, 1-\mathrm{y},-\mathrm{z})$, specific $(\pi$-bonded) dimers of molecules are formed with the distance between planes being 3.46(3) $\AA$ and the dihedral angle $-0^{\circ}$. These dimers are linked with one another through intermolecular interactions between hydrogen atoms H502, H503 of methylene groups of solvate molecule and the oxygen of nitro group O4' ($1+\mathrm{x}, \mathrm{y}, \mathrm{z})$ as well as the oxygen of carbonyl group O82" of other molecule $(-\mathrm{x}, 1-\mathrm{y},-\mathrm{z})$ respectively. The parameters of interaction are d(H502...O4') $2.44 \AA,<\left(\mathrm{C} 50-\mathrm{H} 502 . . \mathrm{O} 4\right.$ ') $141^{\circ}$ and $\mathrm{d}$ (H523...O82”) $2.57 \AA,<\left(\mathrm{C} 52-\mathrm{H} 523 . . \mathrm{O} 82^{\prime \prime}\right) \quad 148^{\circ}$ respectively. Thus, a two-dimensional network of weak intermolecular interactions is formed in the crystal in the form of a layered structure (Figure 4). These layers are located in the $0 a b$ plane of the unit cell with the parallel arrangement of the tricyclic fragments of the molecules. 


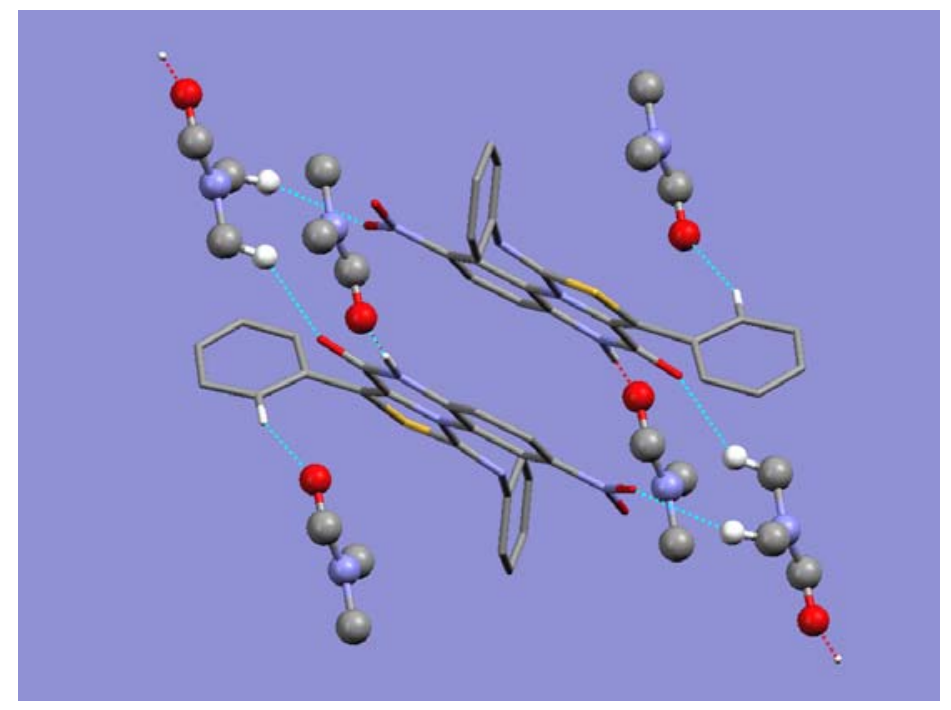

Figure 4. The crystal-packing fragment of compound (2) showing intermolecular hydrogen bonding and layer formation. Hydrogen atoms which do not participate in hydrogen bonding are omitted.

The mutual arrangement of molecules in crystal is characterized by the parallel packing of layered supramolecular structures mentioned above along the $O z$ crystallographic axis. It is interesting to note that in such a type of molecular packing the localization of hydrophilic and lipophilic regions is also observed. The more hydrophobic fragments of the molecules are located between the layers of hydrogen-bonded molecules.

1-Arylimino-3-phenyl-7-methyl-4,5-dihydro-2-oxo-thiazolo[3,4-a]quinoxaline (3). As distinct from previous compounds, the molecules of (3) crystallize without involvement of solvate molecules. The molecule is in a general position in the crystal. However the plane of the tricyclic fragment of the molecule is essentially distorted. In particular, the deviations of the S2 and N1 atoms from the plane of tricycle by $-0.208(2) \AA$ and $0.273(5) \AA$, occur on different sides of the plane, respectively. The atoms $\mathrm{C} 3$ and $\mathrm{C} 3 \mathrm{a}$ are deviated by $-0.380(7) \AA$ and $-0.204(7) \AA$ respectively from the tricycle plane. The dihedral angle between the tricycle plane and the phenyl ring (C31-C36) is 43.5(3) $)^{\circ}$. During the refinement of the crystal structure of compound (3) it was clarified, that second phenyl substituent is disordered over two equivalent positions (one of the possible positions is shown in Figure 5).

The system of hydrogen bonding in (3) is essentially different from that observed in the previous compounds. The basic hydrogen bonding motive in the crystal are the dimers of molecules formed by a pair of hydrogen bonds of a N-H...O type between two molecules linked by the symmetry operation $(2-\mathrm{x},-\mathrm{y}, 1-\mathrm{z})$, with the following parameters of interaction: $\mathrm{d}(\mathrm{H} 5 \ldots \mathrm{O} 4)$ $1.79(3) \AA,<(\mathrm{N} 5-\mathrm{H} 5 . \mathrm{O} 4) 164^{\circ}$. This type of interaction is characteristic of such a type of structures and practically leads to the lack of other types of interactions between molecules in the crystal. 


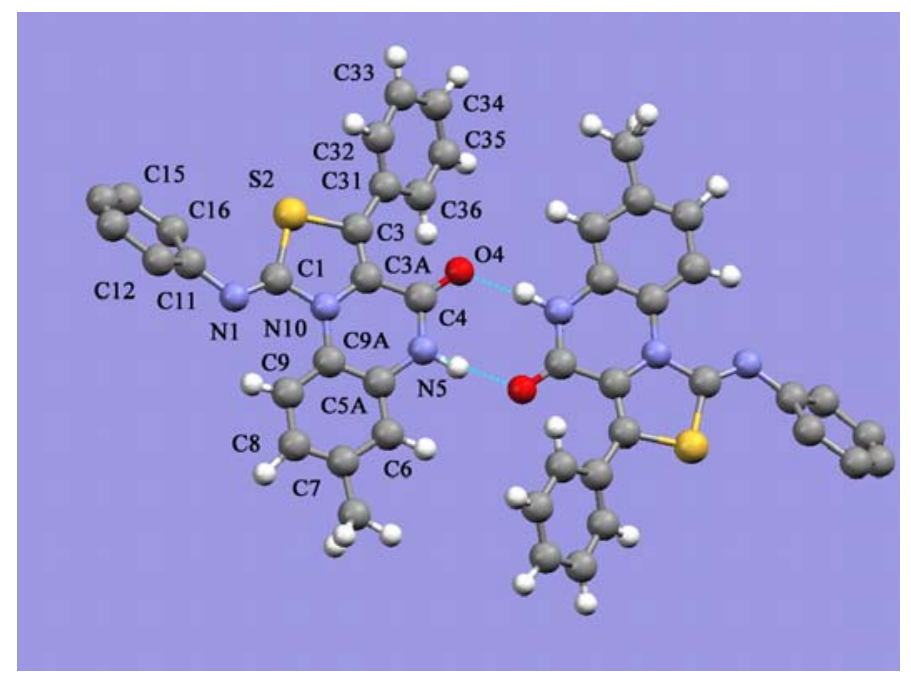

Figure 5. Geometry of the molecule (3) in the crystal and hydrogen-bonded dimer formation. Dashed lines show hydrogen bonds.

Contacts of the $\pi-\pi$ type between molecules result in the formation of sloping stacks of dimers of molecules along a crystallographic axis $0 x$. These stacks represent supramolecular fragments of a cylindrical (rod-like) type. In terms of such fragments the supramolecular structure in the crystal (3) can be represented as tetragonal type antiparallel packing of such rods (Figure 6). It should be also noted that the localization of areas with various degrees of lipophilicity has been observed which is similar to that of other compounds mentioned above. The central part of these rod-like fragments consist of the hydrophilic tricyclic parts of molecules and surrounded by the hydrophobic shell with phenyl substituents of molecules.

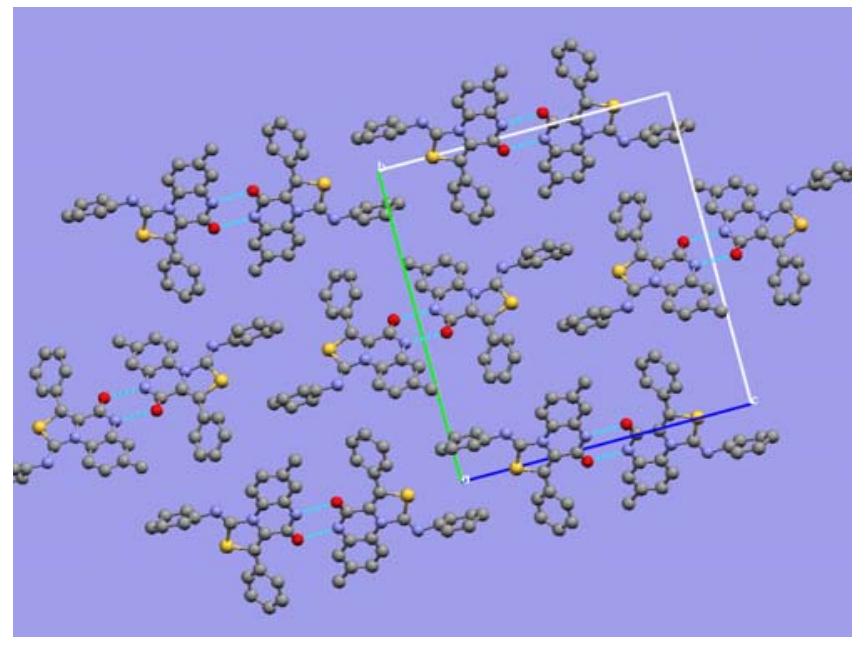

Figure 6. The crystal packing fragment of compound (3) showing rod-like supramolecular structures. 
These compounds are of interest as such. Besides we have used them to verify our previous model based on the phenomenon of the localization of hydrophilic and hydrophobic regions in $\operatorname{organic}_{\text {crystals }^{7-9}}$. It is known that such separation is observed in liquid crystals and in polymers. The ordered structures formed by block copolymers, ${ }^{11}$ consisting of large blocks of mutually repulsive covalently bonded polymer chains are an examples of such type of segregation. Due to competition between the repulsion and attraction they are self-organized into microphase separated structures. Two chemically different blocks repel, which is the reason for most polymer mixtures to phase separate. ${ }^{12,13}$ The covalent bond prohibits phase separation at a macroscopic level. Simple A-block-B copolymers self-organize into various morphologies as illustrated in Figure 7. ${ }^{11,14,15}$ At low volume fractions of block $\mathrm{A}, \varphi \mathrm{A}$, the system is initially disordered, i.e., the small A-block dissolves in the B-block. Increasing $\varphi A$ results in small spheres of $A$ in the matrix of B formation. Upon further increase of the length of the A-block, the system undergoes a change from a spherical to a cylindrical morphology and finally to a lamellar microphase near $\varphi A=0.5$. More complex morphologies, such as the bicontinuous gyroid phase, perforated lamellae and the (metastable) modulated lamellae, ${ }^{16-17}$ are found in a narrow composition window between lamellae and cylinders for sufficiently small values of the FloryHuggins parameter $\chi_{\mathrm{AB}}$. This parameter describes the strength of the enthalpic interaction between A and B. ${ }^{12}$ The research in the block copolymer field has evolved from simple diblock copolymers to triblock- and multiblock copolymers and to block copolymers of a more complex architecture such as star and comb copolymers.

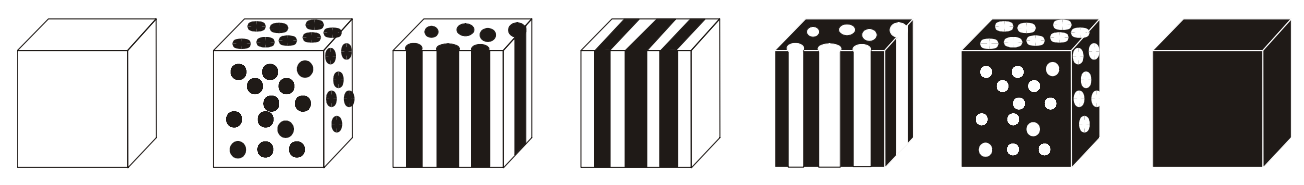

Figure 7. Schematic representation of superlattice types in diblock-copolymers.

The above approach was used by us for the analysis of the supramolecular structure of organic crystals. It should be noted that this refers not only to compounds with a discrete distribution of hydrophilic and hydrophobic fragments in molecules, but also to molecules with their arbitrary distribution over molecular fragments. We have found the localization of hydrophilic and hydrophobic regions in crystals of phosphorus containing heterocyclic systems and have shown, ${ }^{10}$ that the type of superstructure depends on the hydrophilic-hydrophobic volume ratio calculated for molecular fragments. In the compounds considered the superstructures spanning all possible types of superstructures - the completely hydrophilic structure, the packing of hydrophilic cylinders and spherical areas in the hydrophobic matrix, the lamellar type with alternating hydrophilic and hydrophobic layers and inverse structures down to the completely hydrophobic structure, have been observed. Further analysis of this phenomenon showed its versatility and applicability for the description of the supramolecular structure and topology of crystals. ${ }^{18}$ A similar separation was observed in crystalline compounds belonging to 
other classes, in particular substituted calixresorcinearenes, ${ }^{8,19}$ carbocyclic compounds. ${ }^{20}$ This allows to predict the possible topology of crystalline compounds not as yet obtained in the solid crystalline phase.

In order to extend the data to a wider range of compounds we have carried out calculations for compounds which do not give single crystals suitable for X-ray single crystal diffraction (compounds 7, 8). Table 1 demonstrates the data for compounds $(\mathbf{1}, \mathbf{2}, \mathbf{3})$ as well as the data for compounds (4-6) published earlier. For compounds $(7,8)$ we shall try to predict the topological type of structure, possible for their crystals via the calculation of the ratio between hydrophilic and hydrophobic fragments based on the structural formula of these compounds. It is reasonable to assume that the distribution of such fragments should not depend on molecular conformations in a crystal. Further experiments on crystal growth and X-ray diffraction data will help to verify the validity of our asssumptions.

Summarizing the data in table 1 it might be noted that lamellar structures are typical for compounds $(2, \mathbf{1}, 5)$, the calculations predict exactly this type of topology. Only for compound (3) the formation of cylindrical (column-like) hydrophilic supramolecular structures in the hydrophobic matrix is observed. For compounds (4) and (6) the analysis indicates the formation of more complicated perforated topology. The numerical data obtained for compounds (7) and (8) allows to assume the formation of cylindrical supramolecular structures in their crystals. 
Table 1. Representation of crystal packing in the frame of the hydrophilic - hydrophobic areas localization model (red - hydrophobic and blue - hydrophilic fragments of the molecules

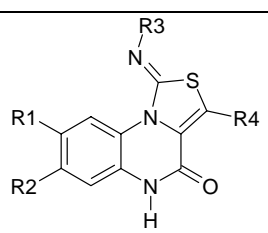

2

$\mathrm{R}_{1}=\mathrm{NO}_{2}, \mathrm{R}_{2}=\mathrm{H}$

$\mathrm{R}_{3}=\mathrm{Ph}, \mathrm{R}_{4}=\mathrm{Ph}$

\section{3}

$\mathrm{R}_{1}=\mathrm{H}, \mathrm{R}_{2}=\mathrm{Me}$

$\mathrm{R}_{3}=\mathrm{Ph}, \mathrm{R}_{4}=\mathrm{Ph}$

\section{1}

$\mathrm{R}_{1}=\mathrm{H}, \mathrm{R}_{2}=\mathrm{H}$

$\mathrm{R}_{3}=\mathrm{Ph}, \mathrm{R}_{4}=\mathrm{Ph}$

$4^{5}$

$\mathrm{R}_{1}=\mathrm{H}, \mathrm{R}_{2}=\mathrm{H}$

$\mathrm{R}_{3}=\mathrm{H}, \mathrm{R}_{4}=\mathrm{Ph}$

$5^{6}$

$\mathrm{R}_{1}=\mathrm{F}, \mathrm{R}_{2}=\mathrm{F}$

$\mathrm{R}_{3}=\mathrm{Ph}, \mathrm{R}_{4}=\mathrm{Ph}$

$$
6^{21}
$$

$\mathrm{R}_{1}=\mathrm{H}, \mathrm{R}_{2}=\mathrm{H}$

$\mathrm{R}_{3}=\mathrm{Me}, \mathrm{R}_{4}=\mathrm{Ph}$

$\mathrm{S}->\mathrm{C}-\mathrm{C}(\mathrm{O}) \mathrm{Me}$

7

$$
\mathrm{R}_{1}=\mathrm{F}, \mathrm{R}_{2}=\mathrm{Mf}
$$$$
\mathrm{R}_{3}=\mathrm{Ph}, \mathrm{R}_{4}=\mathrm{Ph}
$$

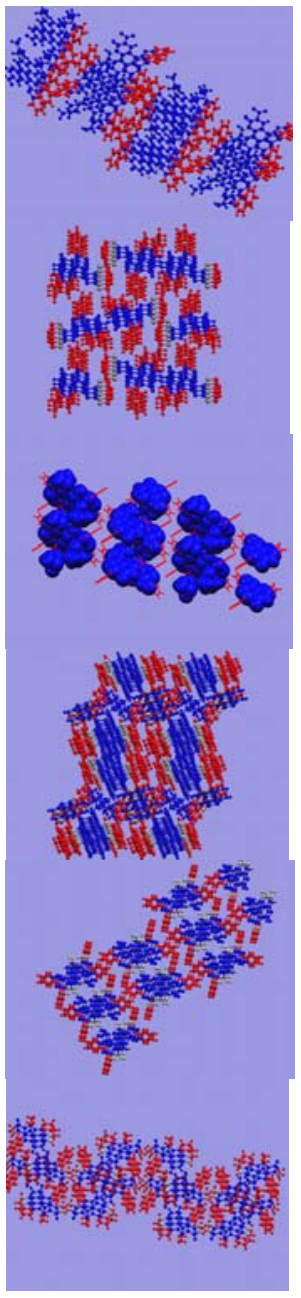

\section{Volume}

fraction of

hydrophilic

fragments

0.60

0.42

0.59

0.65

0.49

0.46

8

$\mathrm{R}_{1}=\mathrm{F}, \mathrm{R}_{2}=\mathrm{F}$

0.67

$\mathrm{R}_{3}=$ thiazol, $\mathrm{R}_{4}=\mathrm{Py}$ 


\section{Conclusions}

On the basis of the data obtained it is possible to draw some important conclusions.

The formation of flattened tricyclic fragments in compounds (2) with a nitro group substituent and in (1) with no substituent in a condensed benzene ring is observed. The conjugation in the tricyclic system is presumably the cause of its planarity. The shift of the electronic density from the methyl group in methyl-substituted compound (3) results in the decrease of conjugation degree and in tricyclic fragment twistening. This is evident from the greater degree of piramidality of the nitrogen atom and the elongation of the S-C bonds and of some other ones. The redistribution of electron density in the molecule (3) results in diminishing the dihedral angle between the plane of tricycle and the phenyl ring, i.e. to the conjugation of these fragments.

Apparently the system of hydrogen bonding in these compounds is first of all determined not by the type of the substituents, but by the presence of solvate molecules in crystals. On the whole, the formation of molecular dimers due to a couple of N-H...O type interactions is characteristic of compounds of a similar type. In most cases this results in the lack of other interactions. The presence of solvate molecules in the crystal hinders dimer formation and at the same time promotes various types of interactions in a crystal.

It is interesting to note, that an identical type of supramolecular structure is formed (layers of hydrogen-bonded molecules) in crystals with solvate molecules. The formation of cylindrical (rod-like) structure is characteristic of an individually crystallized compound (1). Thus the factor of packing of molecules in a crystal appears the highest $(0.71)$ for the nitro-substituted compound with DMF (2), a little bit lower for (1) with DMSO - 0.67, and, apparently, the lowest for individual (3). The disordering of phenyl substituents has not allowed calculating its value, however the presence of disordering as such can testify to the low packing coefficient of molecules in this crystal.

A common property of the investigated structures is the influence of amphiphilic properties of compounds on the packing of molecules, resulting in the localization of hydrophilic and hydrophobic areas in crystals and the formation of various types of superstructures. The type of superstructure depends on the hydrophilic-hydrophobic volume ratio, calculated for molecular fragments. The probable explanation for this fact is the tendency towards the formation of maximally extended domains, admissible and accessible for a given type of symmetry, with predominant hydrophilic or hydrophobic properties. The analysis of the distribution of the formed structures in the compounds under investigation and similar compounds, available in the Cambridge crystallographic database, suggest that the theory, developed for the description of microphase separation in polymeric heterogeneous systems, can be used not only for the analysis of the packing of molecules of organic compounds in a crystals, but also for the prediction of the type of molecular packing. The manifestation of the amphiphilic properties of molecules can be considered an additional principle of the formation of crystalline packing. 


\section{Experimental Section}

General Procedures. 1-Arylimino-3-phenyl-4,5-dihydro-2-oxo-thiazolo[3,4-a]quinoxalines $(1,2,3)$ were prepared by the method reported in the literature. ${ }^{22}$

X-Ray structure determination. The X-Ray diffraction data for the crystals of $(1,2,3)$ were collected on a CAD4 Enraf-Nonius automatic diffractometer using graphite monochromated radiation. The details of crystal data, data collection and refinement are given in Table 2 . The stability of crystals and experimental conditions was checked every 2 hours using three control reflections, while the orientation was monitored every 200 reflections by centering two standards. No significant decay was observed. Corrections for Lorentz and polarization effects were applied. Absorption correction was not applied. The structures were solved by direct methods using $\mathrm{SIR}^{23}$ and $\mathrm{MolEN}^{24}$ packages. All non-hydrogen atoms were refined anisotropically. $\mathrm{H}$-atoms, located in $\Delta \mathrm{F}$ maps, were included in the structure factor calculations with fixed positional and thermal parameters for the crystal of $(2,3)$ and were refined isotropically for the crystal (1). The figures were made using the program suite WinGX ${ }^{25}$ and Mercury $^{26}$. 
Table 2. Crystal data and structure refinement for compounds $(1,2,3)$

\begin{tabular}{|c|c|c|c|}
\hline Parameter & 1 & 2 & 3 \\
\hline Chemical formula & $\mathrm{C}_{22} \mathrm{H}_{15} \mathrm{~N}_{3} \mathrm{OS}$ DMSO & $\mathrm{C}_{22} \mathrm{H}_{14} \mathrm{~N}_{4} \mathrm{O}_{3} \mathrm{~S} \cdot \mathrm{DMF}$ & $\mathrm{C}_{23} \mathrm{H}_{17} \mathrm{~N}_{3} \mathrm{OS}$ \\
\hline Chemical formula weight & 447.58 & 487.54 & 383.48 \\
\hline Space group & $\mathrm{P} 2{ }_{1} / \mathrm{n}$ & $\mathrm{P} 2{ }_{1} / \mathrm{n}$ & $\mathrm{P} 2_{1} / \mathrm{c}$ \\
\hline Crystal system & & Monoclinic & \\
\hline Unit cell dimensions: & & & \\
\hline$a(\AA)$ & $8.355(2)$ & $9.602(2)$ & $4.857(7)$ \\
\hline$b(\AA)$ & $9.371(4)$ & 8.781(3) & 20.42(1) \\
\hline$c(\AA \hat{)})$ & $28.25(4)$ & $28.069(4)$ & 19.137(6) \\
\hline$\beta(\operatorname{deg})$ & 93.19(3) & $92.64(1)$ & $96.11(7)$ \\
\hline $\mathrm{V}\left(\AA^{3}\right)$ & $2209(2)$ & 2364(1) & 1887(3) \\
\hline Z & & 4 & \\
\hline $\begin{array}{l}\text { Density (calculated) } D_{x} \\
\left(\mathrm{mg} \mathrm{m}^{-3}\right)\end{array}$ & 1.35 & 1.70 & 1.35 \\
\hline $\mathrm{F}(000)$ & 936 & 1016 & 800 \\
\hline Crystal form & needle & prismatic & needle \\
\hline Crystal size (mm) & $0.4 \times 0.2 \times 0.1$ & $0.4 \times 0.2 \times 0.05$ & $0.35 \times 0.1 \times 0.1$ \\
\hline Diffractometer used & & Enraf-Nonius CAD-4 & \\
\hline Radiation $(\AA)$ & 1.54184 & 0.71073 & 1.54184 \\
\hline Temperature, (deg K) & & $294(2)$ & \\
\hline Recording range $\theta_{\max }(\mathrm{deg})$ & 49.81 & 21.97 & 57.22 \\
\hline Absorption correction & & not applied & \\
\hline$\mu\left(\mathrm{cm}^{-1}\right)$ & 2.35 & 1.68 & 1.62 \\
\hline No. of recorded reflections & 2475 & 4701 & 8212 \\
\hline $\begin{array}{l}\text { No. of independent } \\
\text { reflections with } \mathrm{F}^{2} \geq 3 \sigma\left(\mathrm{F}^{2}\right)\end{array}$ & 1531 & 1216 & 1575 \\
\hline $\mathrm{R}(\%)$ & 0.051 & 0.046 & 0.053 \\
\hline $\mathrm{R}_{\mathrm{w}}(\%)$ & 0.059 & 0.046 & 0.054 \\
\hline Goodness of fit, S & 1.365 & 1.14 & 1.264 \\
\hline
\end{tabular}


Table 3. Selected bond lengths $[\AA]$, angles $\left[{ }^{\circ}\right]$ and torsion angles $\left[{ }^{\circ}\right]$ for compounds $(\mathbf{1}, \mathbf{2}, \mathbf{3})$

\begin{tabular}{|c|c|c|c|}
\hline & 1 & 2 & 3 \\
\hline \multicolumn{4}{|c|}{ Bond lengths } \\
\hline $\mathrm{S} 2-\mathrm{C} 1$ & $1.765(4)$ & $1.744(7)$ & $1.806(7)$ \\
\hline $\mathrm{S} 2-\mathrm{C} 3$ & $1.746(5)$ & $1.737(8)$ & $1.795(6)$ \\
\hline $\mathrm{N} 1-\mathrm{C} 1$ & $1.272(6)$ & $1.279(9)$ & $1.270(8)$ \\
\hline $\mathrm{N} 1-\mathrm{C} 11$ & $1.404(6)$ & $1.442(9)$ & $1.449(7)$ \\
\hline N5-C4 & $1.347(5)$ & $1.385(9)$ & $1.387(9)$ \\
\hline N5-C5a & $1.393(5)$ & $1.379(9)$ & $1.420(9)$ \\
\hline N10-C1 & $1.392(5)$ & $1.401(9)$ & $1.456(8)$ \\
\hline $\mathrm{N} 10-\mathrm{C} 3 \mathrm{a}$ & $1.430(5)$ & $1.390(9)$ & $1.382(8)$ \\
\hline N10-C9a & $1.434(5)$ & $1.417(8)$ & $1.424(9)$ \\
\hline \multicolumn{4}{|c|}{ Bond angles } \\
\hline $\mathrm{C} 1-\mathrm{S} 2-\mathrm{C} 3$ & $92.5(2)$ & $91.8(3)$ & $93.8(3)$ \\
\hline $\mathrm{C} 3 \mathrm{a}-\mathrm{C} 3-\mathrm{C} 31$ & $131.6(4)$ & $131.1(7)$ & $136.8(5)$ \\
\hline C4-N5-C5a & $125.1(4)$ & $125.8(6)$ & $125.7(5)$ \\
\hline N5-C4-C3a & $115.6(4)$ & $113.0(6)$ & $111.6(6)$ \\
\hline C1-N10-C9a & $125.4(3)$ & $123.7(6)$ & $122.3(5)$ \\
\hline C3a-N10-C9a & $120.7(3)$ & $120.2(5)$ & $122.2(5)$ \\
\hline C3-C3a-C4 & $126.3(4)$ & $125.8(7)$ & $119.7(6)$ \\
\hline C5a-C9a-C9 & $119.7(4)$ & $117.1(6)$ & $120.3(6)$ \\
\hline N1-C1-N10 & $127.3(4)$ & $126.2(6)$ & $126.9(6)$ \\
\hline N10-C3a-C4 & $119.9(3)$ & $122.2(6)$ & $122.4(6)$ \\
\hline $\mathrm{N} 10-\mathrm{C} 3 \mathrm{a}-\mathrm{C} 3$ & $113.8(4)$ & $112.0(6)$ & $117.6(5)$ \\
\hline \multicolumn{4}{|c|}{ Torsion angles } \\
\hline C3-S2-C1-N10 & $3.2(3)$ & $4.7(5)$ & $-0.4(5)$ \\
\hline C1-S2-C3-C3a & $-2.9(3)$ & $-3.9(6)$ & $-2.0(5)$ \\
\hline C5a-N5-C4-C3a & $-4.3(6)$ & $1.8(9)$ & $-0.2(9)$ \\
\hline C4-N5-C5a-C9a & $1.5(6)$ & $-4(1)$ & $-6(1)$ \\
\hline C3a-N10-C1-S2 & $-2.8(4)$ & $-4.7(7)$ & $2.8(6)$ \\
\hline C9a-N10-C1-N1 & $0.1(6)$ & $-0(1)$ & $8(1)$ \\
\hline C1-N10-C3a-C3 & $0.7(5)$ & $2.0(8)$ & $-4.8(9)$ \\
\hline C9a-N10-C3a-C4 & $-3.7(5)$ & $-2.7(9)$ & $-15(1)$ \\
\hline C1-N10-C9a-C9 & $-4.7(6)$ & $-3(1)$ & $4(1)$ \\
\hline C3a-N10-C9a-C5a & $0.8(5)$ & $0.4(9)$ & $8.4(9)$ \\
\hline N10-C3a-C4-N5 & $5.3(5)$ & $1.7(9)$ & $10.4(9)$ \\
\hline $\mathrm{S} 2-\mathrm{C} 3-\mathrm{C} 31-\mathrm{C} 32$ & $-124.5(4)$ & $-120.6(6)$ & $41.0(8)$ \\
\hline
\end{tabular}




\section{Supplementary Material Available}

Crystallographic data for the structures $(\mathbf{1}, \mathbf{2})$ and $(3)$ reported in this paper have been deposited with the Cambridge Crystallographic Data Centre and have been allocated deposition numbers CCDC 181759 - 181761 respectively. Copies of the data can be obtained free of charge on application to CCDC, 12 Union Road, Cambridge CB2 1EZ, UK [fax: +44(0) 1223-336033 or email: deposit@ccdc.cam.ac.uk].

\section{Acknowledgements}

The authors are grateful to the Russian Fund for Fundamental Research [grants 02-03-32280 (A.T.G.) and 03-03-32865 (V.A.M.)] for financial support of this study.

\section{References}

1. Ohloff, G.; Flament, I. Heterocycles 1978, 11, 663.

2. Barlin, G.B. Chemistry of Heterocyclic Compounds; Weisberger, A.; Taylor, E.C. Eds.;Wiley Interscience: Chichester, New York, 1979; Vol. 35.

3. Kurasava, I.; Takada, A.; Kim, H.S. Journal of Heterocyclic Chemistry 1995, 32, 1085.

4. Kleim, J-P.; Bender, R.; Billhardt, U-M.; Meichsner, C.; Riess, G.; Rosner, M.; Winkler, I.; Paessens, A. Antimicrobial Agents and Chemotherapy 1993, 1659.

5. Mamedov, V.A.; Kalinin, A.A.; Gubaidullin, A.T.; Nurkhametova, I.Z.; Litvinov, I.A.; Levin, Ya. A. Khimiya Heterocycl. Soed. (Rus.) 1999, 12, 1664.

6. Mamedov, V.A.; Nurkhametova, I.Z.; Kotovskaya, S.K.; Gubaidullin, A.T.; Levin, Ya. A.; Litvinov, I.A.; Charushin, V.N. Russ. Chem. Bull. in press $(\mathbf{2 0 0 4}, 11)$.

7. Gubaidullin, A.T.; Morozova, Y.E.; Kazakova, E.Kh.; Litvinov, I.A. Materials Structure 1998, 5, 398.

8. Gubaidullin, A.T.; Morozova, Y.E.; Mustafina, A.R.; Kazakova, E.Kh.; Litvinov, I.A.; Konovalov, A.I. Mendeleev Commun. 1999, 1, 9.

9. Gubaidullin, A.T.; Litvinov, I.A. Acta Cryst. 2000, A56, 318.

10. Mironov, V.F.; Gubaidullin, A.T.; Schtyrlina, A.A.; Litvinov, I.A.; Petrov, R.R.; Konovalov, A.I.; Dobrynin, A.B.; Zyablikova, T.A.; Musin, R.Z.; Morozov, V.I. Zh. Obshch. Khim. (Russ. J. Gen. Chem.) 2002, 72, 1868.

11. Fredrickson, G. H.; Bates, F. S. Ann. Rev. Mater. Sci. 1996, 26, 501.

12. de Gennes, P.-G. Scaling Concepts in Polymer Physics; Cornell University Press: Ithaca; 1979.

13. Flory, P. J. Principles of Polymer Chemistry; Cornell Univerisity Press: Ithaca, 1971. 
14. (a) Frenkel, S. J.Polym.Sci., Polym. Symp. 1977, 61, 327. (b) Sadron, Ch.; Gallot, B. Makromol. Chem. 1973, 164, 301.

16. Hajduk, D. A.; Harper, P. E.; Gruner, S. M.; Honeker, C. C.; Kim, G.; Thomas, E. L.; Fetters, L. J. Macromolecules 1994, 27, 4063.

17. Qi, S.; Wang, Z.-G. Phys. Rev. E 1997, 55, 1682.

18. Gubaidullin, A.T.; Litvinov, I.A. XVII Mendeleev Congress on Pure and Applied Chemistry; Kazan, Russia, Abstracts 2003, 1, 252.

19. Gubaidullin, A.T.; Nikolaeva, I.L.; Burilov, A.R.; Litvinov, I.A.; Pudovik, M.A.; Habicher, W.D.; Konovalov, A.I. Russ. J. Gen. Chem. 2001, 71, 396.

20. Gubaidullin, A.T.; Mamedov, V.A.; Litvinov, I.A.; Ye, H.; Tsuboi, S. Monatsh. Chemi. 2003, 134, 1229.

21. Mamedov, V.A.; Kalinin, A.A.; Gubaidullin, A.T.; Litvinov, I.A.; Azancheev, N.M.; Levin, Ya. A. Rus. J. Org. Chem. (Rus) 2004, 1, 123.

22. Mamedov, V.A.; Nurkhametova, I.Z.; Gubaidullin, A.T.; Litvinov, I.A.; Tsuboi, S. Heterocycles 2004, 63, 1783.

23. Altomare, A.; Cascarano, G.; Giacovazzo, C.; Viterbo, D. Acta Crystallogr. 1991, A47, 744.

24. Straver, L. H.; Schierbeek, A. J. MOLEN. Structure Determination System; Nonius B.V.; Delft, The Netherlands, 1994.

25. Farrugia, L.J. WinGX Version 1.64.05. J.Appl.Crystal. 1999, 32, 837.

26. Bruno, I. J.; Cole, J. C.; Edgington, P. R.; Kessier, M.K.; Macrae, C. F.; McCabe, P.; Pearson, J.; Taylor, R. Acta Crystallogr. 2001. B57, 815. 